\section{Preparation of a partially avulsed scalp}

Sir,

Scalp avulsions are usually associated with individuals having long hair, which, apart from being the reason for the injury, is also an impediment to the treating surgeon attempting to salvage the injured scalp. ${ }^{[1]}$ Methods have been described to remove hair from a totally avulsed scalp. ${ }^{[2,3]}$ However, on a partially avulsed scalp, the same cannot be done as the injured part that needs to be shaved cannot be separated from the cranium. We present a simple

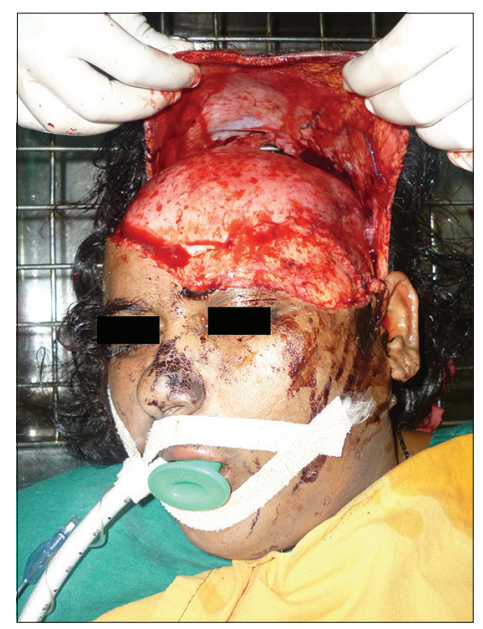

Figure 1: Lifting off the avulsed scalp

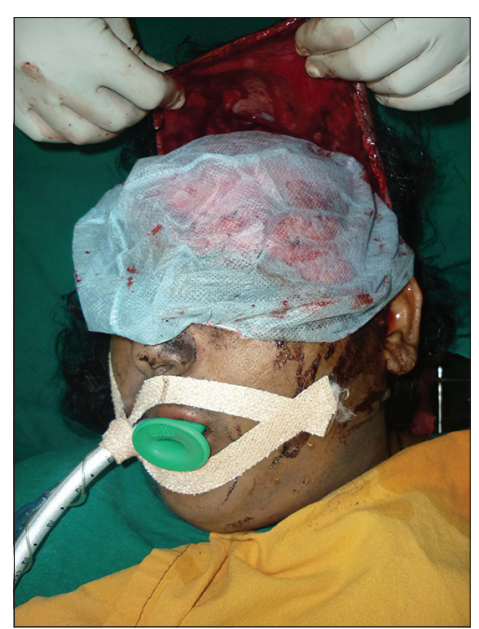

Figure 2: Placement of a clean surgical cap

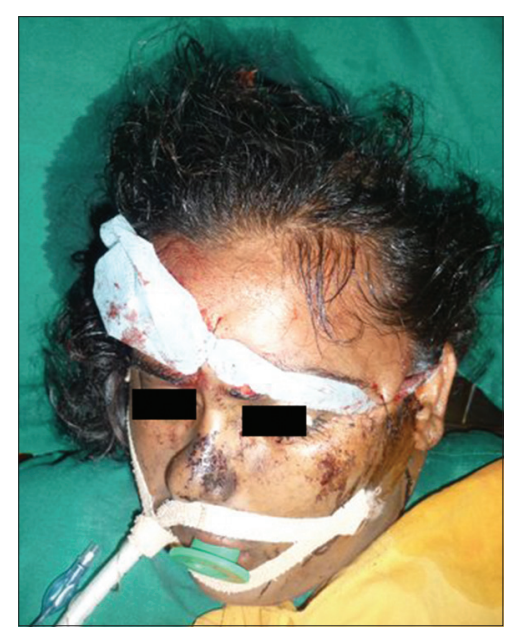

Figure 3: Degloved scalp anchored back with temporary sutures

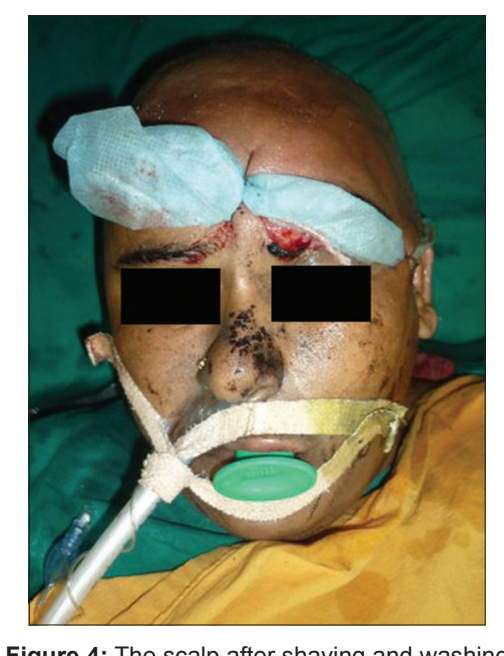

Figure 4: The scalp after shaving and washing

modification of the above methods for the preparation of a near totally avulsed scalp with only an occipital strip of skin attachment. The anaesthetized patient is positioned exposing the avulsed scalp which is lifted off the cranium [Figure 1]. A clean disposable surgical cap is the placed 


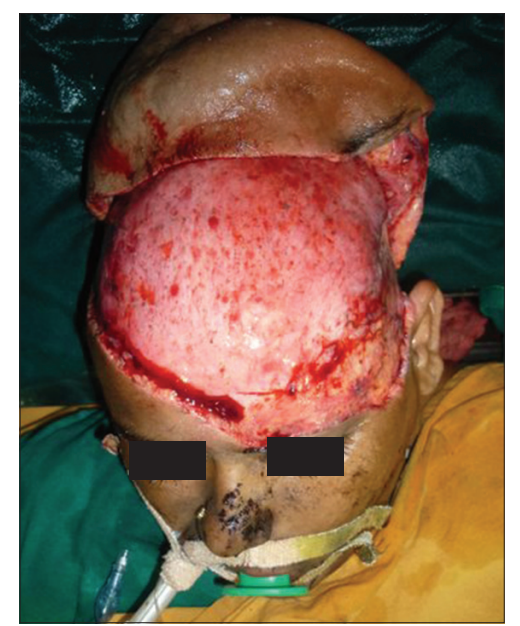

Figure 5: Uncontaminated subcutaneous tissue

over the cranium carefully tucking the distal part under the pedicle of the scalp [Figure 2]. The avulsed scalp is then re-draped over the cap and fixed to the skin with temporary anchoring sutures [Figure 3]. The scalp is then shaved and washed to remove all loose hair [Figure 4]. The outer surface of the scalp is then painted and the same is done for the inner layers after removal of the anchoring sutures and the protective cap [Figure 5]. The head is then draped in sterile drapes and is positioned for surgery.

\section{Madhu Periasamy, Hari Venkatramani, Raja S. Sabapathy}

Department of Plastic Surgery, Ganga Hospital, Coimbatore, Tamil Nadu, India

Address for correspondence: Dr. Madhu Periasamy, Department of Plastic Surgery, Ganga Hospital, 313, Mettupalayam Road, Coimbatore, Tamil Nadu, India.

\section{REFERENCES}

E-mail: madhuperiasamy@gmail.com

1. Sabapathy SR, Venkatramani H, Bharathi RR, D'Silva J. Technical considerations in replantation of total scalp avulsions. J Plast Reconstr Aesthet Surg 2006;59:2-10.

2. Venkatramani H, Sabapathy SR. A simple method of shaving avulsed scalp before replantation. Plast Reconstr Surg 2001;107:286.

3. Bhaskara KG, Patil R, Vinoth P. Modified method of shaving an avulsed scalp before replantation. J Plast Reconstr Aesthet Surg 2008;61:850-1.

\begin{tabular}{|l|l|}
\multicolumn{3}{|c|}{ Access this article online } \\
\hline Quick Response Code: & Website: \\
\hline & www.ijps.org \\
\cline { 2 - 2 } & DOl: \\
\hline
\end{tabular}

